\title{
Prevalence and association of anxiety and depression among orthopaedic trauma inpatients: a retrospective analysis of 1994 cases
}

Yun Yang ${ }^{1 \dagger}$, Ting-ting Tang ${ }^{1,2+}$, Mei-ru Chen ${ }^{1,2}$, Mao-ying Xiang ${ }^{1,2}$, Ling-li Li $i^{1,2}$ and Xiao-ling Hou ${ }^{1,2^{*}}$

\begin{abstract}
Background: Patients with traumatic injuries are often accompanied by emotional disorders, which seriously impede functional gains. The objective of this study was to identify the prevalence and risk factors associated with underlying anxiety and depression in orthopaedic trauma patients.

Methods: From July 2015 to December 2017, all orthopaedic trauma patients were included in the retrospective study. Patients with conditions that might affect cognitive impairment were excluded from the study. Basic demographic data were collected. All patients were screened for emotional disorders on admission using a simple questionnaire called "Huaxi Emotional-Distress Index" (HEI). Bivariate analyses and logistic regression were used to identify the factors associated with a HEl score of $>8$.

Results: One hundred and sixty-two patients (8.1\%) had a HEl score of $>8$. About $1.0 \%$ of enrolled patients had severe emotional disorders (HEl score $\geq 17$ ). The reasons caused by emotional disorders in patients with orthopaedic trauma were a higher Injury Severity Score (ISS), a higher visual analogue score (VAS) and type of surgery. On logistic regression, marital status was a protective factor for emotional disorders, while VAS and ISS were the risk factors for emotional disorders.

Conclusions: Although a significantly low percentage of orthopaedic trauma patients in our setting have emotional disorders, traumatic orthopaedic surgeons still need to pay attention to the risk of emotional disorders and integrate effective screening tools into clinical practice to screen for these factors and stratify emotional disorders. Appropriate targeted psychological intervention and treatment should be adopted according to the stratification of emotional disorders.
\end{abstract}

Keywords: Anxiety, Depression, Prevalence, Risk factors, Orthopaedic trauma

\footnotetext{
* Correspondence: 296825257@qq.com

†Yun Yang and Ting-ting Tang contributed equally to this work and should be considered co-first authors.

'Department of Orthopaedics, West China Hospital, Sichuan University,

Chengdu, Sichuan, People's Republic of China

${ }^{2}$ School of Nursing, West China Hospital of Sichuan University, Chengdu,

Sichuan, People's Republic of China
}

(c) The Author(s). 2020 Open Access This article is licensed under a Creative Commons Attribution 4.0 International License, which permits use, sharing, adaptation, distribution and reproduction in any medium or format, as long as you give appropriate credit to the original author(s) and the source, provide a link to the Creative Commons licence, and indicate if changes were made. The images or other third party material in this article are included in the article's Creative Commons licence, unless indicated otherwise in a credit line to the material. If material is not included in the article's Creative Commons licence and your intended use is not permitted by statutory regulation or exceeds the permitted use, you will need to obtain permission directly from the copyright holder. To view a copy of this licence, visit http://creativecommons.org/licenses/by/4.0/ The Creative Commons Public Domain Dedication waiver (http://creativecommons.org/publicdomain/zero/1.0/) applies to the data made available in this article, unless otherwise stated in a credit line to the data. 


\section{Background}

With the improvement of surgical techniques and the development of implants, significant advancements have been made in the management of orthopaedic trauma patients. However, orthopaedic surgeons tend to focus on physical and technical factors in the treatment of these musculoskeletal injuries. In fact, drastic physical changes, strange hospital environment and uncertainty of post-injury recovery affect patients' psychology. Anxiety and depression in orthopaedic trauma patients have been reported to range between $5-35 \%$ and $13-56 \%$, respectively [1-3]. Some studies have found that emotional disorder (anxiety or depression) was associated with factors such as pain, nuclear family, female sex [4], severity of injury [5], a younger age, lack of social support and use of cannabis [6,7]. Several studies have established these psychological factors adversely affect the outcomes [8-10]. Therefore, it is of great significance to understand and master the psychological characteristics and related factors of orthopaedic trauma patients in order to promote rapid rehabilitation.

At present, while there are many scales for screening anxiety, depression and negative emotions [11-14], few scales can screen these three aspects at the same time. In addition, these scales are rarely used in routine clinical practice due to their disadvantages, which include too many items, time consumption and cultural or language barriers. Therefore, based on the Chinese population and culture, Wang et al. [15] developed a new psychometrically solid and concise screening tool for identifying emotional disorders (anxiety, depression and/ or suicidal ideation). The questionnaire was named as "Huaxi Emotional-Distress Index (HEI)". The Cronbach's $\alpha$ of HEI was 0.90 ; sensitivity and specificity were 0.880 and 0.766 , respectively. The HEI has shown good effectiveness when used in patients or medical staff, which is characterized by fewer items, less time and easy accessibility $[15,16]$.

Early detection of emotional disorders in patients is crucial as it gives medical staff a chance to further improve and promote clinical medical treatment and nursing work. Therefore, this study's aim was to determine the prevalence of underlying emotional disorders among orthopaedic trauma inpatients and identify related factors at a level 1 trauma centre.

\section{Materials and methods}

\section{Subjects}

A retrospective evaluation was conducted of orthopaedic trauma patients between July 2015 and December 2017. The inclusion criteria were as follows: (1) age greater than or equal to 15 years and (2) musculoskeletal injuries (including fracture, joint dislocation and soft tissue injuries of nerve, muscle, blood vessel, etc.). Patients with conditions that might affect cognitive impairment were excluded from the study. These included conditions such as head injury, chronic neurological illness, history of psychiatric disorder, chronic ongoing illness and intellectual disability. The questionnaire was conducted only when patients reported physical comfort. Data were collected through an anonymous way because the patients' identifiers such as name and unique identity were erased. Before the study began, we had carefully consulted the Ethics Committee and Institutional Review Board of West China Hospital. They suggested that this study did not involve special interventions for patients and we should conduct this study in compliance with the Helsinki Declaration. So, all data was fully anonymised at source. Given the anonymous nature of the data, the ethics committee waived any requirement for patient informed consent.

\section{Huaxi emotional-distress index}

The HEI is a preliminary screening tool for emotional disorders (anxiety and depression) in non-psychiatric clinical settings [15]. It is mainly used for rapid screening and grading of emotional disorders and related mental health problems. There are 9 self-reported items in total that can be finished in less than $5 \mathrm{~min}$. All items are 5-point Likert-scaled with scale points $0,1,2,3$ and 4. The total score is the sum of the scores of 9 items. There are four grades based on the total score: normal (0-8 points), mild (9-12 points), moderate (13-16 points) and severe (17-36 points). If there is a relatively serious emotional disorder, it will automatically expand to 11 items. The last 2 additional items are not included in the score, but the results are for the reference of clinical workers. Details of the HEI are shown in Table 1.

\section{Assessment method}

Generally, the paper version of the questionnaire was sent to patients, who filled in the results according to their actual situation. If the patient had difficulty completing the questionnaire, such as a hand injury, the nurse staff would help fill in the questionnaire according to their dictation. Then, the nursing staff uploaded the results filled out by the patient to the HIS system, and the doctors of mental health centre checked the patient's filling results through the HIS system and timely feedbacked the report. For patients with mild to moderate emotional disorder, psychological counselling should be conducted first by nurses who have received psychological training and obtained certificates. When necessary, psychiatric consultation was conducted for specialized treatment. A more systematic suicide risk assessment was required if the score of the 9th item was equal to or higher than 2 or if the score indicated a severe emotional disorder and the score was verified to 
Table 1 Huaxi Emotional-Distress Index (HEl)

\begin{tabular}{|c|c|c|c|c|c|c|}
\hline \multicolumn{2}{|r|}{ Items } & $\begin{array}{l}\text { Never } \\
\text { (0 point) }\end{array}$ & $\begin{array}{l}\text { Occasionally } \\
\text { (1 point) }\end{array}$ & $\begin{array}{l}\text { Some of the time } \\
\text { ( } 2 \text { points) }\end{array}$ & $\begin{array}{l}\text { Most of the time } \\
\text { ( } 3 \text { points) }\end{array}$ & $\begin{array}{l}\text { Nearly all the time } \\
\text { (4 point) }\end{array}$ \\
\hline \multicolumn{7}{|c|}{ 1. Felt so depressed that nothing could cheer you up? } \\
\hline \multicolumn{7}{|c|}{ 2. Had no interest or pleasure in doing things? } \\
\hline \multicolumn{7}{|l|}{ 3. Felt very nervous? } \\
\hline \multicolumn{7}{|c|}{ 4. Felt not being able to control worrying? } \\
\hline \multicolumn{7}{|c|}{ 5. Felt too restless to calm down? } \\
\hline \multicolumn{7}{|c|}{ 6. Felt scared that the sudden panic or fear would attack again? } \\
\hline \multicolumn{7}{|l|}{ 7. Blamed yourself? } \\
\hline \multicolumn{7}{|l|}{ 8. Felt hopeless? } \\
\hline \multicolumn{7}{|c|}{ 9. Felt meaningless in living? } \\
\hline \multirow{2}{*}{ Two additional items } & \multicolumn{6}{|c|}{$\begin{array}{l}\text { 10. How much did you think your negative emotions (anxiety, depression, etc.) had affected your life in the past month? } \\
\begin{array}{lllll}\text { A. No impact } & \text { B. Small impact } & \text { C. Some impact } & \text { D. Greater impact } & \text { E. Huge impact }\end{array}\end{array}$} \\
\hline & \multicolumn{6}{|c|}{$\begin{array}{l}\text { 11. What were the main reasons for the above emotional problems (bad mood, worry, etc.) in the past month (multiple } \\
\text { choices)? } \\
\text { A. Physical health problems (pain, chronic diseases - diabetes, asthma, hypertension, etc., surgery, chemoradiotherapy for tumors, } \\
\text { etc.) } \\
\text { B. Love, marriage and family problems (death of a loved one, illness of a family member, failure in love or marriage, difficulty in } \\
\text { educating children, etc.) } \\
\text { C. Occupational or academic problems (Entrance pressure, financial problems, occupational pressure, etc.) } \\
\text { D. Interpersonal tension } \\
\text { E. Others }\end{array}$} \\
\hline
\end{tabular}

reflect the patient's true feelings. For these patients, psychiatric consultation and specialized treatment were the first steps. Secondly, a weekly questionnaire was required during the hospitalization. The detailed process was shown in Fig. 1.

\section{Statistical analysis}

Statistical analysis of the data was performed using the SPSS 20.0 software (SPSS Chicago, IL, USA). The statistical methods adopted included frequency, percentage (\%), mean \pm standard, $t$ test, univariate analysis, correlation analysis and multiple linear regression analysis. A value of $p \leq 0.05$ was considered to be statistically significant.

\section{Results}

According to the inclusion and exclusion criteria, 1994 patients were included in the study. The age ranged

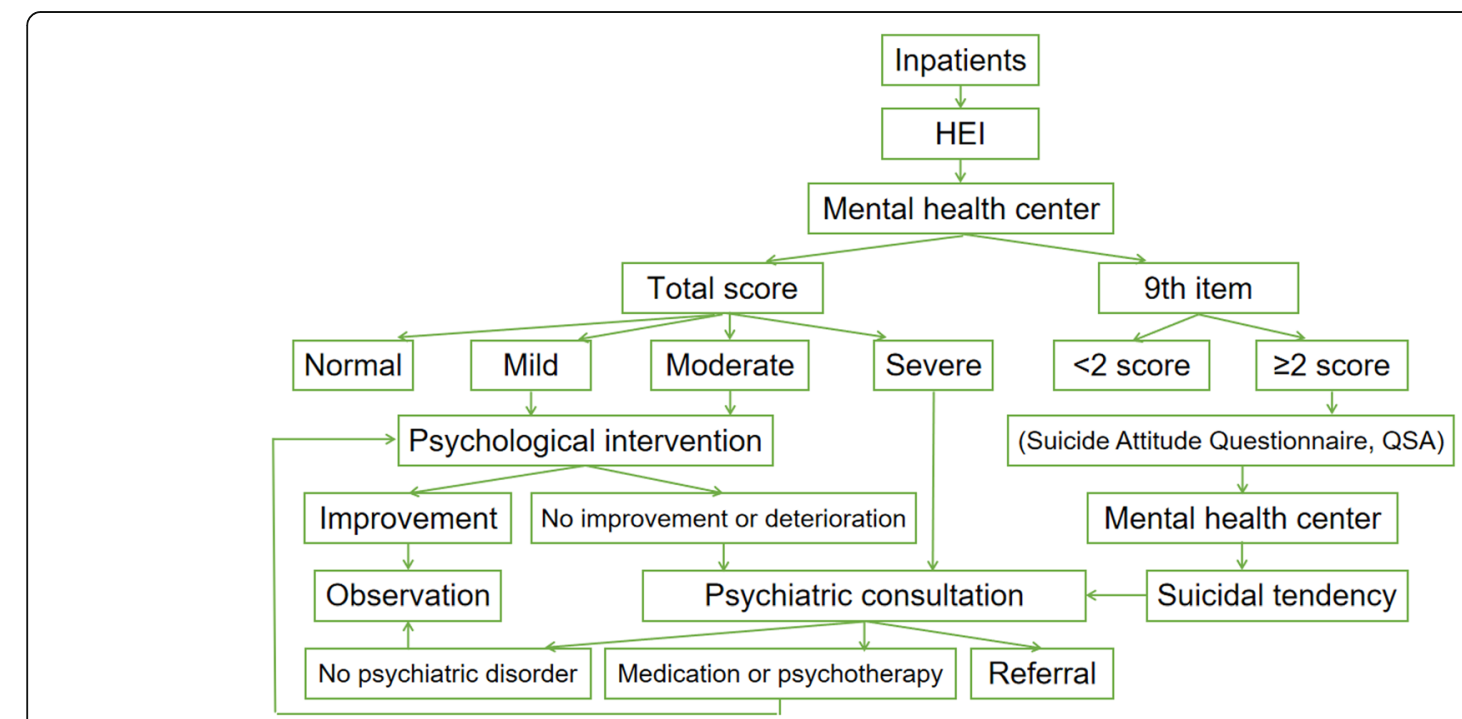

Fig. 1 The process of HEl assessment and coping strategies 
from 15 to 90 , with an average age of $47.8 \pm 17.5$. Nearly two thirds of the patients were males. The vast majority (87.71\%) of patients were admitted to hospital with fractures. The average Injury Severity Score (ISS) was $8.0 \pm$ 4.4. Nearly $75 \%$ of the patients had a high school degree or less. Nearly a third of the patients (34.7\%) required emergency surgery. Baseline data of the enrolled patients were shown in Table 2.

One hundred and sixty-two patients (8.1\%) had a HEI score of $>8$ (Table 2). Twenty patients had a score of $\geq 17$,

Table 2 The baseline data of the enrolled patients

\begin{tabular}{ll}
\hline Variables & \\
\hline Age (years) & $360(18.06 \%)$ \\
$\leq 29$ & $753(37.76 \%)$ \\
$30-49$ & $881(44.18 \%)$ \\
$\geq 50$ & \\
Gender & $1317(66.05 \%)$ \\
Male & $677(33.95 \%)$ \\
Female & $7.97 \pm 4.44$ \\
Injury Severity Score (ISS) & $6.52 \pm 1.24$ \\
Mean pain score at admission (VAS) & \\
Types of musculoskeletal injury & $1749(87.71 \%)$ \\
Fracture & $99(4.97 \%)$ \\
Joint dislocation & $146(7.32 \%)$ \\
Soft tissue injuries & \\
Educational level & $618(30.99 \%)$ \\
Primary school or below & $892(44.73 \%)$ \\
High school & $254(12.74 \%)$ \\
Junior college & $173(8.68 \%)$ \\
Undergraduate & $25(1.25 \%)$ \\
Graduate or higher & $32(1.61 \%)$ \\
Others &
\end{tabular}

\section{Marital status}

Married

Unmarried

$1603(80.39 \%)$

Divorced or widowed

294 (14.75\%)

$97(4.86 \%)$

\section{Surgery}

\section{Emergency}

Elective

None

692 (34.70\%)

$1249(62.64 \%)$

$53(2.66 \%)$

\section{HEl score}

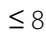

$>8$

Total

If joint dislocation and fracture occurred at the same time, it was considered If joint dislocation and fracture occurred at the same time, it was conside secondary school. Others in educational level referred to patients who did not want to disclose their education suggesting that about $1.0 \%$ of patients with orthopaedic trauma had severe emotional disorders. A higher ISS, a higher visual analogue score (VAS) and type of surgery were found to be significantly associated $(p$ value $<0.05)$ with a HEI score of $>8$ (Table 3 ). Because 32 patients did not want to disclose their educational levels, we treated these patients as missing values here (Table 4).

Stepwise logistic regression was used to identify significant predictors of HEI $>8$. Marital status was a protective factor for emotional disorders. Specifically, the risk of emotional disorders in married patients was 0.5 times that of unmarried patients, while divorced or widowed patients had a 0.4 times higher risk than unmarried patients. The VAS and ISS were risk factors for emotional disorders. The risk of emotional disorders increased by 1.2 times and 1.1 times, respectively, for every 1 point increase in these two factors (Table 5).

\section{Discussion}

Orthopaedic trauma is an unforeseen life-changing event [17] that can disrupt multiple dimensions of healthrelated quality of life. Nearly 2.8 million Americans sustain traumatic orthopaedic injuries annually [18]. In addition to limited physical activity, these patients are often interfered with social roles, pain and emotional disorders [19]. Although significant advancements have been made in the treatment of orthopaedic injuries [20,21], high rates of disability following musculoskeletal injury remain prevalent. Current orthopaedic trauma research has been substantially focused on rapid stabilization of the patient and reconstruction of musculoskeletal tissues. Although physical trauma can be effectively treated, emotional disorders in orthopaedic trauma inpatients are often ignored and impede functional recovery [10]. A growing body of literature has pointed to the substantial importance of psychosocial factors in recovery from traumatic orthopaedic injuries [8-10]. Therefore, efficient screening and early identification of emotional disorders are helpful for orthopaedic trauma surgeons to take active and effective interventions to prevent adverse events, with a view to improving outcomes.

In our study, the frequency of emotional disorders (HEI score $>8$ ) was $8.1 \%$. Our result was much lower than the prevalence of emotional disorders (anxiety and depression) reported in other studies $[4,10,22,23]$. This was likely due to the heterogeneity of the populations studied and the instruments used to measure these psychological parameters [24, 25]. In addition, there were some objective practical reasons that might explain the relatively low prevalence. On the one hand, many patients came to our hospital with high expectations of good physical function due to their great trust in our hospital. On the other hand, a significant number of patients were referred from other hospitals or lower-level 
Table 3 Association between the level of HEI score and related factors

\begin{tabular}{|c|c|c|c|}
\hline Variables & HEI score $\leq 8(n(\%))$ & HEI score > $8(n(\%))$ & $p$ value \\
\hline Age (years) & $48.00 \pm 17.44$ & $45.84 \pm 17.78$ & 0.172 \\
\hline \multicolumn{4}{|l|}{ Gender } \\
\hline Male & $1212(66.16 \%)$ & $105(64.81 \%)$ & \multirow[t]{2}{*}{0.729} \\
\hline Female & $620(33.84)$ & 57 (35.19\%) & \\
\hline Injury Severity Score (ISS) & $7.84 \pm 4.42$ & $9.54 \pm 4.37$ & $<0.001$ \\
\hline Mean pain score at admission (VAS) & $6.48 \pm 1.25$ & $6.88 \pm 1.12$ & $<0.001$ \\
\hline \multicolumn{4}{|l|}{ Types of musculoskeletal injuries } \\
\hline Fracture & $1606(87.67 \%)$ & $143(88.27 \%)$ & \multirow[t]{3}{*}{0.708} \\
\hline Joint dislocation & $93(5.07 \%)$ & $6(3.70 \%)$ & \\
\hline Soft tissue injuries & $133(7.26)$ & $13(8.03)$ & \\
\hline \multicolumn{4}{|l|}{ Marital status } \\
\hline Married & 1481 (80.84\%) & $14(8.64 \%)$ & \multirow[t]{3}{*}{0.051} \\
\hline Unmarried & $268(14.63 \%)$ & $26(16.05 \%)$ & \\
\hline Divorced or widowed & $83(4.53 \%)$ & $122(75.31 \%)$ & \\
\hline \multicolumn{4}{|l|}{ Surgery } \\
\hline Emergency & $626(34.17 \%)$ & $66(40.74 \%)$ & \multirow[t]{3}{*}{0.027} \\
\hline Elective & $1161(63.37 \%)$ & $88(54.32 \%)$ & \\
\hline None & 45 (2.46\%) & 8 (4.94\%) & \\
\hline
\end{tabular}

hospitals and received initial treatment. At the same time, the data of the included cases in this study were all from the first questionnaire of the patients at the time of admission. Thus, those patients with no emotional disorders at the time of admission developed negative emotions during the hospitalization, and these patients were not included in the study. These reasons may result in a low prevalence of emotional disorders.

On logistic regression, we found the VAS, ISS and marital status to be associated with a HEI score $>8$. A study of multivariable analysis reported that a higher pain score, nuclear family and female sex were associated with depression in orthopaedic trauma patients [4]. Another study reported that only open fractures had an effect on the presence of depression among injuryspecific factors [10]. Giannoudis et al. [5] found that the

Table 4 Association of the level of education with HEl score $>8$

\begin{tabular}{llll}
\hline & HEI score $\leq \mathbf{8}$ & HEI score $>\mathbf{8}$ & $\boldsymbol{p}$ value \\
\hline Educational level & & & \\
Primary school or below & $574(31.85 \%)$ & $44(27.50 \%)$ & 0.936 \\
High school & $806(44.73 \%)$ & $86(53.75 \%)$ & \\
Junior college & $234(12.99 \%)$ & $20(12.50 \%)$ & \\
Undergraduate & $164(9.10 \%)$ & $9(5.63 \%)$ & \\
Graduate or higher & $24(1.33 \%)$ & $1(0.62 \%)$ \\
Total & $1802(100 \%)$ & $160(100 \%)$ & \\
\hline
\end{tabular}

Because 32 patients did not want to disclose their educational levels, we treated these patients as missing values here and did not include univariate analysis presence of anxiety was related to the severity of injury in the lower extremity. Other studies found that a younger age, lack of social support and use of cannabis were positively correlated with depression $[6,7]$. We did not find any association between age and sex and HEI score.

Pain has a detrimental effect on patients' quality of life as it often leads to emotional disorders such as anxiety and depression. Although the link between depression and chronic pain has been well established [26], similar research on acute musculoskeletal pain is limited. We found a significant positive association between acute post-traumatic pain and HEI score $>8$, which was consistent with the results reported in other literature [4, 27]. In our experience, patients were most likely to exhibit catastrophic thinking and became anxious or depressed when in pain, which in turn exacerbated the pain, leading to a vicious cycle. To this end, for orthopaedic trauma patients, it is necessary to actively manage pain to reduce anxiety or depression.

A few studies have found no relationship between depression and ISS $[4,10]$. However, we found ISS to be significantly positively associated with HEI $>8$ score. In this study, these patients with severe injuries had relatively complex conditions, such as open fractures or multiple fractures. These patients had long hospital stays, which contradicted their desire for good physical function, and were prone to negative emotions. For such patients, in addition to the first questionnaire at admission, a weekly questionnaire was often required during the hospitalization in order to timely find out potential negative emotions and deal with them accordingly. 
Table $\mathbf{5}$ Logistic regression analysis showing the relationship of significant emotional distress (anxiety and/or depression) predictors with HEI score $>8$

\begin{tabular}{lllll}
\hline & $\boldsymbol{B}$ & S.E. & $\boldsymbol{p}$ value & Exp (B)/OR \\
\hline Injury Severity Score (ISS) & 0.060 & 0.020 & 0.002 & 1.062 \\
Mean pain score at admission (VAS) & 0.162 & 0.076 & 0.034 & 1.175 \\
Marital status & & & 0.022 & 0.487 \\
$\quad$ Married & -0.720 & 0.361 & 0.046 & 0.425 \\
$\quad$ Divorced or widowed & -0.855 & 0.310 & 0.006 & 0.039 \\
Constant & -3.239 & 0.544 & 0.000 & \\
\hline
\end{tabular}

Several studies have reported the relationship between social and family support and depression $[6,28]$. In our study, marital status was found to be associated with HEI $>8$ on logistic regression. The unmarried patients had a higher risk of emotional disorders than those married patients. The loss of family support resulted in physical and psychological isolation. Unmarried patients tended to have negative emotions because they felt isolated. A good family atmosphere was beneficial to the improvement of patients' negative emotions, especially for those who were seriously damaged and needed more care and company from their families or partners. In this study, the patients might feel that their families, especially their children, provided them with increased social support after acute orthopaedic trauma, and the patients were satisfied with this support. This might be related to the importance attached to filial piety in traditional Chinese culture. These might well explain the low incidence of emotional disorders in this study.

This study has several limitations. First, some baseline characteristics (such as alcohol abuse, smoking, economic status) were not included in the study. Second, data were collected from a single level 1 trauma centre and may affect their representativeness and consistency. Third, this study did not include some other possible psychological variables, such as post-traumatic stress disorder common to orthopaedic trauma patients. Therefore, further research could expand the coverage and diversity of samples and increase layers of research design.

\section{Conclusion}

This study uses a new psychometrically solid and concise screening tool that effectively and efficiently screens emotional disorders. In high-risk groups, such as patients with a higher ISS, higher pain score or being unmarried, it is especially important for providers to be aware of the possible negative effect of emotional disorders on patient outcomes. Although a significantly low percentage of orthopaedic trauma patients in our setting have emotional disorders, we recommend emotional screening and stratification for inpatient orthopaedic trauma patients. According to the stratification of emotional disorders, appropriate targeted psychological intervention and treatment should be adopted.

\begin{abstract}
Abbreviations
HEI: Huaxi Emotional-Distress Index; ISS: Injury Severity Score; VAS: Visual analogue scale/score
\end{abstract}

\section{Acknowledgements}

The authors thank Wen-zhu Li in providing language help.

\section{Authors' contributions}

$Y Y, \Pi$ and $X H$ provided the ideas of this study. $Y Y, \Pi, M C$ and $M X$ collected the data. $Y Y$ and $\Pi$ analysed the data. $L L$ and $X H$ helped with the interpretation of the data. $\mathrm{LL}$ and $\mathrm{XH}$ provided the funding. All authors read and approved the final manuscript.

\section{Funding}

This study was supported by the Sichuan Province Science and Technology Support Program of China (Grant No. $2018 S 20246$ to Xiao-ling Hou, Grant No. 2020YFS0153 to Ling-li Li).

Availability of data and materials

Datasets are available from the corresponding author on reasonable request.

Ethics approval and consent to participate

Before the study began, we had carefully consulted the Ethics Committee and Institutional Review Board of West China Hospital. They suggested that this study did not involve special interventions for patients, and we should conduct this study in compliance with the Helsinki Declaration and inform patients fully of the purpose of the study. So, all data was fully anonymised at source with researchers. Given the anonymous nature of the data, the ethics committee waived any requirement for patient informed consent.

\section{Consent for publication}

Not applicable.

\section{Competing interests}

The authors declare that they have no competing interests.

Received: 14 October 2020 Accepted: 29 November 2020

Published online: 07 December 2020

\section{References}

1. Vincent HK, Hagen JE, Zdziarski-Horodyski LA, Patrick M, Sadasiva KK, Guenther R, et al. Patient-reported outcomes measurement information system outcome measures and mental health in orthopaedic trauma patients during early recovery. J Orthop Trauma. 2018;32(9):467-73.

2. Weinberg DS, Narayanan AS, Boden KA, Breslin MA, Vallier HA. Psychiatric illness is common among patients with orthopaedic polytrauma and is linked with poor outcomes. J Bone Joint Surg Am. 2016;98:341-8.

3. McCrabb S, Baker AL, Balogh ZJ, Lott N, Palazzi K, Naylor J, et al. Comorbid tobacco and other substance use and symptoms of anxiety and depression among hospitalized orthopaedic trauma patients. BMC Psychiatry. 2019; 19(28):1-9.

4. Kumar S, Verma V, Kushwaha U, Calvello Hynes EJ, Arya A, Agarwal A. Prevalence and association of depression in in-patient orthopaedic trauma patients: a single centre study in India. J Clin Orthop Trauma. 2020;11(Suppl 4):S573-7.

5. Giannoudis PV, Harwood PJ, Kontakis G, Allami M, Macdonald D, Kay SP et al. Long-term quality of life in trauma patients following the full 
spectrum of tibial injury (fasciotomy, closed fracture, grade IIIB/IIIC open fracture and amputation). Injury. 2009;40(2):213-9.

6. Becher S, Smith M, Ziran B. Orthopaedic trauma patients and depression: a prospective cohort. J Orthop Trauma. 2014;28(10):e242-6.

7. Gobbi G, Atkin T, Zytynski T, Wang S, Askari S, Boruff J, et al. Association of cannabis use in adolescence and risk of depression, anxiety, and suicidality in young adulthood: a systematic review and meta-analysis. JAMA Psychiatry. 2019;76(4):426-34

8. Gokce A, Bekler H, Karacaoglu E, Servet E, Gokay NS. Anxiety and trauma perception and quality of life in patients who have undergone replantation. J Reconstr Microsurg. 2011;27(8):475-80.

9. Meijer DT, Gevers Deynoot BDJ, Stufkens SA, Sierevelt IN, Goslings JC, Kerkhoffs GMMJ, et al. What factors are associated with outcomes scores after surgical treatment of ankle fractures with a posterior malleolar fragment? Clin Orthop Relat Res. 2019:477(4):863-9.

10. Crichlow RJ, Andres PL, Morrison SM, Haley SM, Vrahas MS. Depression in orthopaedic trauma patients-prevalence and severity. J Bone Joint Surg. 2006;88(9):1927-33.

11. Kroenke K, Spitzer RL, Williams JBW. The PHQ-9. J Gen Intern Med. 2001;16: 606-13.

12. Spitzer RL, Kroenke K, Williams JW, Löwe B. A brief measure for assessing generalized anxiety disorder: the gad-7. Arch Intern Med. 2006;166:1092-7.

13. Beck AT, Steer RA, Brown GK. Beck Depression Inventory-II. San Antonio: Psychological Corporation; 1996.

14. Zigmond AS, Snaith RP. The hospital anxiety and depression scale. Acta Psychiatr Scand. 1983;67:361-70.

15. Wang J, Guo WJ, Zhang L, Deng W, Wang HY, Yu JY, et al. The development and validation of Huaxi emotional-distress index (HEl): a Chinese questionnaire for screening depression and anxiety in nonpsychiatric clinical settings. Compr Psychiatry. 2017;76:87-97.

16. Dong ZQ, Ma J, Hao YN, Shen XL, Liu F, Gao Y, et al. The social psychological impact of the COVID-19 pandemic on medical staff in China: a cross-sectional study. Eur Psychiatry. 2020;63(1):e65.

17. Maselesele VM, Idemudia ES. The role of social support in the relationship between mental health and posttraumatic stress disorder amongst orthopaedic patients. Curationis. 2013;36(1):E1-7.

18. Hall MJ, DeFrances CJ, Williams SN, Golosinskiy A, Schwartzman A. National Hospital Discharge Survey: 2007 summary. Natl Health Stat Rep. 2010;29:124.

19. Kaske S, Lefering R, Trentzsch H, Driessen A, Bouillon B, Maegele M, et al. Quality of life two years after severe trauma: a single-centre evaluation. Injury. 2014:45(Suppl 3):S100-5.

20. Wegener ST, Carroll EA, Gary JL, McKinley TO, O’Toole RV, Sietsema DL, et al. Trauma collaborative care intervention: effect on surgeon confidence in managing psychosocial complications after orthopaedic trauma. J Orthop Trauma. 2017;31(8):427-33.

21. Castillo RC, Wegener ST, Newell MZ, Carlini AR, Bradford AN, Heins SE, et al. Improving outcomes at level I trauma centers: an early evaluation of the Trauma Survivors Network. J Trauma Acute Care Surg. 2013;74(6):1534-40.

22. de Moraes VY, Jorge MR, Faloppa F, Belloti JC. Anxiety and depression in Brazilian orthopaedics inpatients: a cross sectional study with a clinical sample comparison. J Clin Psychol Med Settings. 2010;17(1):31-7.

23. McCarthy ML, MacKenzie EJ, Edwin D, Bosse MJ, Castillo RC, Starr A, LEAP study group. Psychological distress associated with severe lower-limb injury. J Bone Joint Surg Am. 2003;85(9):1689-97.

24. Beleckas CM, Wright M, Prather H, Chamberlain A, Guattery J, Calfee RP. Relative prevalence of anxiety and depression in patients with upper extremity conditions. J Hand Surg Am. 2018;43(6):571.e1-8.

25. Degen RM, MacDermid JC, Grewal R, Drosdowech DS, Faber KJ, Athwal GS. Prevalence of symptoms of depression, anxiety, and posttraumatic stress disorder in workers with upper extremity complaints. J Orthop Sports Phys Ther. 2016;46(7):590-5.

26. Zis P, Daskalaki A, Bountouni I, Sykioti P, Varrassi G, Paladini A. Depression and chronic pain in the elderly: links and management challenges. Clin Interv Aging. 2017;12:709-20.

27. Michaelides A, Zis P. Depression, anxiety and acute pain: links and management challenges. Postgrad Med. 2019;131(7):438-44.

28. Husain N, Humail SM, Chaudhry IB, Rahman R, Robinson H, Creed F. Psychological distress among patients of an orthopaedic outpatient clinic: a study from a low-income country. Ann General Psychiatry. 2010;9:9.

\section{Publisher's Note}

Springer Nature remains neutral with regard to jurisdictional claims in published maps and institutional affiliations.

\section{Ready to submit your research? Choose BMC and benefit from:}

- fast, convenient online submission

- thorough peer review by experienced researchers in your field

- rapid publication on acceptance

- support for research data, including large and complex data types

- gold Open Access which fosters wider collaboration and increased citations

- maximum visibility for your research: over $100 \mathrm{M}$ website views per year

At $\mathrm{BMC}$, research is always in progress.

Learn more biomedcentral.com/submissions 